Sign Systems Studies 30.1, 2002

\title{
Human/animal communications, language, and evolution
}

\author{
Dominique Lestel \\ Ecole Normale Supérieure, 45 rue d'Ulm, 75005 Paris, France \\ e-mail: Dominique.Lestel@ens.fr
}

\begin{abstract}
The article compares the research programs of teaching symbolic language to chimpanzees, pointing on the dichotomy between artificial language vs. ASL, and the dichotomy between researchers who decided to establish emotional relationships between themselves and the apes, and those who have seen apes as instrumental devices. It is concluded that the experiments with the most interesting results have been both with artificial language and ASL, but with strong affiliation between researchers and animal involved in the experiments. The experiments on talking apes are not so much experiments in psycholinguistics (how far can animal learn human language) but wonderful experiments in the communities of communication between human beings and great apes.
\end{abstract}

Ever since the sixties, American psychologists have been involved in one of the most interesting scientific adventures of the second part of the 20th century: to teach a symbolic language to chimpanzees in order to make them able to communicate with human beings. (1) In the first part of the article, I give a short synthetic presentation of these research programs through two pillars: the dichotomy between artificial language vs. ASL, and the dichotomy between researchers who decided to establish strong emotional relationships between themselves and the apes, and those who have always seen apes as instrumental devices. I show that the experiments with the most interesting results have been both with artificial language and ASL but with strong affiliation between researchers and animal involved in the experiments. (2) Then, I suggest that unlike what has always been 


\section{Dominique Lestel}

said, these experiments on talking apes are not so much experiments in psycholinguistics (how far can animal learn human language) but wonderful experiments in the communities of communication between human beings and great apes. Indeed, for the first time in the history of the world, animals (humans) have tried to build up communities whose only goal is to seriously communicate with another species. (3) In the third part of the paper, I analyse this situation in the context of the evolution of communication and I try to think human language not as a property that puts the human being apart from other living creatures, but as a property that makes human beings able to better communicate with non human living creatures. In conclusion, I analyse the reasons for which this situation is of great importance for proper thinking on the evolution of communication and biosemiotics.

\section{Some introductory remarks on the evolution of communication}

Evolution of communication and language have usually been thought of either from a strict phylogenetic point of view or from a pure cultural point of view. Marc Hauser (1996) wrote a classical work on the topic of the phylogenetic evolution of communication through comparative psychology and ethology of communication, but by the very topic of his book Hauser restricts himself to treat the communicative abilities of a number of species which he sees as significant, particularly among primates and birds. Questions of plasticity of communication are quite neglected as is the possible history of such communicative systems which ornithologists have observed it in the form of so-called dialects among birds. Also interspecific communications are roughly forgotten. Nevertheless, Hauser's approach is a usual one, and I am sure his book is now taken as a classical text-book in the field.

It is much more unusual to mix up both phylogenetic and cultural approaches of communication. To adopt that position means that for other species than humans, communicative competences are seen to have a functional plasticity that allows cultural non-trivial cognitive transformations. I do not wish to discuss the topic of animal culture here, a field of research that have been largely renewed during the last 
years (Lestel, 2001 for a philosophical discussion), but to focus my argumentation on a neglected part of these researches - namely the situation of animals living among humans, animals well adapted in human cultures. Domesticated animals, commensal animals or pets are quite good examples to discuss in that way, but the best one is still the example of the so-called "talking apes" in the USA. In that situation, apes that do not use a symbolic language are able to use it after humans have taught it to them. For the first time in the history of Nature, living beings are now able to use communicative devices taught by other creatures in order to communicate together. Two questions become crucial: what really happens in that operation and what does it mean from an evolutionary point of view?

\section{How apes acquire symbolic languages at the end of the twentieth century}

Since the beginning of the sixties, there have been a few research programs aiming at teaching a symbolic language to non-human primates. Roughly, four different orientations have been adopted by scientists ${ }^{1}$ working in the field.

(a) The first one has been developed by Alan and Beatrix Gardner, from the University of Nevada at Reno, particularly with chimpanzee Washoe. It emphasized the use of ASL as a symbolic medium, and the necessity to establish close affective contacts between human researchers and chimpanzees. Regular experiments were used to complete informal but rigorous training. Trainers could not speak English when chimpanzees are around for example. Extremely draconian criteria were also used to determine that a sign had been acquired by the chimpanzees. ${ }^{2}$ R. Fouts tried to get Washoe to teach ASL to another chimpanzee, namely adopted offspring Loulis, and they exchange signs among themselves without the presence of humans. ${ }^{3}$

${ }^{1}$ Nearly all of them were or are experimental psychologists. The only assured exception is Lyn Miles, who works with orangutan Chantek, and who is an anthropologist by training.

${ }^{2}$ Gardner et al. (1989) summarize 20 years of research on ASL and chimpanzees.

${ }^{3}$ A good overview can be found in Fouts, Fouts 1989. 
(b) The second orientation may be featured by David Premack's research program at University of Santa Cruz and later at University of Pennsylvania. Premack emphasized the use of an artificial symbolic language, especially designed for the experiments, and on a strong separation between animals being tested and human experimenters.

(c) The third orientation has been adopted by Columbia psychologist Herbert Terrace who drew a strong separation between humans and ape (Nim Chimsky) and used ASL taught in formal way (eight hours a day in a classroom of Columbia University).

(d) The fourth orientation is Duane Rumbaugh's and Sue SavageRumbaugh's who have chosen both an artificial language (the Yerkish, a special language designed by professional linguists ${ }^{4}$ ). and the convivial and "familial" approach already adopted by the Gardner. Three projects have done. The first one was the Lana Project, the second one the Animal Model project and the third one the project with the bonobos, in particular with Kanzi.

\section{Experiments on talking apes as experiments on human/animal hybrid communities of communication}

These experiments on talking apes still wait to be interpreted. They are scientific studies whose meaning has to be explored, just as had the meaning of quantum mechanics in twentieth century physics. To describe these experiments only in terms of experiments in psycholinguistics (how far can an ape acquire a human language?) is to greatly impoverish what is at stake. In the coming paragraphs, I wish to indicate some fruitful trails from a biosemiotic point of view.

3.1. In these experiments, each ape has an history. "He" becomes a person. In that way, "he" becomes an "heteronomous strong subject", who communicates to humans his desires, his fears and his joys. In natural settings, as described by field ethologists like Jane Goodall, Christophe Boesch, Tetsuro Matsuzawa and so on, these chimpanzees are "autonomous weak subjects". The notion of heteronomous strong subject sounds like a very curious notion to the ears of western people whose cultural tradition is based upon the association of autonomy

\footnotetext{
${ }^{4}$ For a summary of this work, cf. Rumbaugh, Pate 1984.
} 
and identity. Transfers of affects and emotions are very strong. Humans may explore these apes' subjective landscapes - and the reverse is also possible. That knowledge is a sharing one, although not a symmetrical one. These apes become creatures for which humans have hopes, fears, joys, pains, etc. Empathy between humans and these primates allows a semiotic strong interaction. We have not paid enough attention to a growing practice, concerning wild animals as well as animals like talking apes: the possibility to feature some animals through their biography - which means temporal coherences, behavioural idiosyncrasies and "mental states" (preferences, repulsions, ...) that feature a given animal.

3.2. What is striking in these research programs is the fact that animals and human beings live together in strong communities that we can qualify as hybrid human/animal communities of sharing of meaning, interests and affects. These hybrid communities are first of all semiotic communities.

Changes in the conceptualisation of language are important to understand what I mean by semiotic communities, in particular following Bates (1979) who saw language as a tool to change a listener's behaviour. In that way, language is defined more by what it allows one to do than by what it is. Then, S. Savage-Rumbaugh (1990) can explain that language is a communication system based on causes and effects. Subject learns how to use language, but also how the others use it. What is important is no longer the presumed intention of the speaker, but the interplay of actions generated at the interface between locutor and interlocutors. Language becomes not only a systems of signs, but also a process organizing the behaviour of several interacting individuals. What is needed is a definition of the speaker more than a definition of language. In that way, Savage-Rumbaugh no longer asks if chimpanzees can learn a language, but if they can become effective speakers. Language is not so much a tool to tell somebody else something ${ }^{5}$ but a semiotic tool to live together, and that is also true with animals living among humans.

\footnotetext{
${ }^{5}$ Let us assume that story-tellers and philosophers have a special status in the community.
} 
3.3. It is fruitful to explain an important dimension of these hybrid semiotic communities through a new interpretation of the Turing Test $^{6}$. Alan Turing, the designer of the test was one the brightest British mathematicians of the first part of the twentieth century and a founder of the new academic field of theoretical computer science. $\mathrm{He}$ kept in mind a basic question for a long part of his life, namely the question of how to know in which way a machine can be intelligent, and in which ways humans may have the possibility to discover it. To answer that question, Turing designed a test, the famous Turing test, in order to test the machine's intelligence. A human $H_{1}$, in a room, has to make a decision to know where is another human $H_{2}$ and the machine $\mathrm{M} . \mathrm{H}_{2}$ and the Machine are each located in one of two other rooms. $H_{1}$ is linked with the machine and the human only through an abstract channel, for instance a computer keyboard. $H_{1}$ has to determine who is in which room through questioning $M$ and $H_{2}$. If $H_{1}$ confused $H_{2}$ and $M$, through the answers to his questions, $M$ is said to be an intelligent machine. In that way, Turing developed a cooptative approach of intelligence: an intelligent creature is a creature that/who has been admitted in the community of the intelligent creature by another intelligent creature. The semiotic community does work in the same way: a creature is seen as a semiotic creature if it is allowed to become a member of the community of the semiotic creatures, i.e., if the creature is able to communicate with already admitted members of the community. It is not a vicious circle, because such admittance means a lot of work by both parts in the process, and some basic transformations and results. The notion of cross-fostering family, originally coined by the Gardner ${ }^{7}$, is important here. It refers to the situation in which members of a species raise offspring of another species - here humans raising chimpanzee offspring. This means that belonging to a semiotic community requires learning (sometimes a cultural learning) and is not at all a matter of fact.

3.4. These experiments on talking apes lead to the still rather neglected questions concerning the ability of human language to modify an animal semiotic system. If these experiments clearly show that these apes really "talk", they also clearly show that these apes do

\footnotetext{
${ }^{6}$ Turing (1959).

${ }^{7}$ But the first attempt has been done by the Kelloggs, in which the subjects are chimpanzees and the foster parents are human beings. Cf. Kellogg (1968).
} 
not talk as humans do. The great missing dimension of the analysis of the talking apes experiments is precisely the silence on the essential role that humans play in the process by which some great apes acquire the use of a symbolic language. That dimension has been raised during the $70 \mathrm{~s}$ and the $80 \mathrm{~s}$, but in a very narrow sense as an objection against these studies: it was the so-called "Clever Hans effect". Shortly, that objection points to the possibility that unconscious signals were communicated by humans to animals that would explain the performance of the animal under observation. It must nevertheless be clear that even if the Clever Hans objection does not work, ${ }^{8}$ the role of humans is a basic one in the process through which great apes acquire an access to symbolic language. For instance, if apes are able to communicate with humans or with other apes through symbols, it has been humans that have imposed the conventions underlying their very use.

3.5. It must also be said that some transformations in the process of acquiring symbols are not well understood. One example refers to the natural vocalizations by Kanzi quite different from natural ones: Kanzi vocalizes more and he uses new sounds, unheard in zoos or natural settings for that species. Let's keep also attention to the fact that some animals use to communicate together through symbolic devices learned from humans without their presence - as Washoe and Loulis did.

The philosophical value of these experiments have been largely underestimated. Let us take only two questions which relates them to biosemiotics. Firstly, these experiments threw new light on the status of human being in the biosemiotic sphere, where he alone has a status of "universal interlocutor". Secondly, these experiments open new ways to deal with origins of language.

\footnotetext{
${ }^{8}$ An elegant refutation have been given by experiments in which humans and chimpanzees were communicating together through computer keyboards which put away the possibility of any physical interactions between humans and animals (they were simply not present in the same room. Cf. Savage-Rumbaugh (1986).
} 


\section{4: Human being as a universal interlocutor}

4.1. Language has often been featured by philosophers as "the very proper" of human beings. For them, language allows humans to use self-interpretation and self-transformations that other animals lack and leads to the raising of a radical frontier that divides humans on the one hand and animals on the other.

4.2. It does not mean that animal communications are very primitive ones. Quite a few animals, for instance, have the astonishing ability to manipulate other's semiotic systems and to develop what British primatologists R. Byrne and A. Whiten (1988) have called Machiavellian intelligence, which refers to surprisingly diverse behaviours used to manipulate communication.

4.3. These philosophers have nevertheless neglected another vision of language, not as the basic feature that divides humans and animals but as the ability that allows humans and other animals to get closer together. Through language, humans have the possibility to acquire knowledge on animal communications, to raise a cultural expertise on human/animal interactions and to devise strategies in order to communicate with animals. In that way, human symbolic language transforms humans in universal interlocutors (Lestel 2002) in the field of living beings. Such a situation is possible because both humans and other animals live in the same world. From an evolutionist point of view, we have met similar constraints, different to be sure, but which were of the same nature concerning subsistence and reproduction. Language enables humans to be highly efficient at capturing animals or also at developing a wealth of relations with them on many levels.

4.4. From the neo-Darwinian point of view of the evolution of intelligence, it is striking to realize that animal species that have highly developed semiotic competences and animal species that have highly developed technical competences are almost never the same. For instance singing birds and birds that build complex nests belong to different species. Only two exceptions break the rule: social insects and humans. Among these latter, what characterized humans is that they do not only build complex devices for communicating together but they also build special devices to communicate - and that they 
are the only species to do that. If human beings invent techniques to communicate with other humans, they also invent new technics in order to better communicate with non-human animals. This is a crucial point: Although some birds are able to imitate other's semiotic systems - humans are alone in being able to cleverly use the semiotic systems of potentially all living animals - and not only to blindly imitate them. Humans are therefore universal talkers.

4.5. Humans have also another unique semiotic ability: They alone are building tools that allow non human creatures using different semiotic systems to communicate together to communicate with them, as we saw in the case of talking apes. Thus, humans have developed an elaborated technozoosemiotics. ${ }^{9}$ Let us keep in mind the bells of the shepherds, etc. Such a trend is still alive. Brazilian artist Eduardo Kac, to name just one, have recently tried to design new semiotic devices in order to make humans able to communicate with bats. ${ }^{10}$

\section{Pleasure and evolution of communication}

Whoever observes talking primates as I have done is necessarily struck by the intense pleasure these animals takes in communicating with humans through symbolic devices, which leads one to wonder what role such pleasure may have had in the origins of human language (Lestel 2002). Certain philosophical difficulties are usually underestimated whenever people try to build a theory of the origins of language, and I wish to discuss some of them and to suggest a new approach.

(1) Most theories of the origins of language take for granted that the structural properties that feature human language compared to animal communications are also the causes for the emergence of language. For example, it is because humans can tell stories through languages that language emerged as an evolutionary advantage.

\footnotetext{
${ }^{9}$ The term has been coined by French artist Louis Bec who devoted his artistic activity to design material interfaces to make humans and animals able to communicate together.

${ }^{10}$ That performance was called "Darker Than Night" and has been shown in a bat cave at the Blijdorp Zoological Gardens, Rotterdam, as part of the exhibition "Fables of a Technological Era". On that performance, cf. Milevska (2000).
} 


\section{Dominique Lestel}

(2) All theories on the origins of language fail to take into account its historical dimension. There are no good reasons given in favour of the hypothesis that languages as we know them are only a result of a phylogenetical evolution - on the contrary.

(3) Adaptative advantages attributed to language consider that language has to be thought of as a break away from animal communication. We must be careful about our reasonings: how do we deal with animal communication? Have we explored possibilities to think animal communication without reducing it to a kind of sub-human communication? Let's take an example. Ethologists usually think of animal communication through the glasses of instrumental rationality: what do animals try to tell others in order to reach which goal? An alternative possibility is largely underdiscussed: animal communication does not convey any information to others, but is only a way by which the animal expresses its own affective situation. Not at all: "Be careful, predators!" but: "I am afraid because of predators". In that way, animals have developed an emotional rationality (not an instrumental one), and the so-called messages by animals are taken as events by others.

(4) This leads more generally to the questions of knowing "who talks"? In particular are "subjects" necessarily talking subjects or might we observe "speechless subjects"?

(5) The broadly accepted assumption that the origin of language must be looked for in the functional utilities it provides have to be discussed. In this paper I wish to suggest another story which insists upon pleasure as obtained by language use rather than on strict functional utility. I shall put forward four arguments for this view. The first one will be behaviours that strike any observer of so-called "talking apes" namely the extreme pleasure taken by the primates under observation in the use of a symbolic language to interact with humans. The second one will be the possibility that emerge, from a neurophysiological point of view, that brain areas of language and pleasure are quite similar: around the Broca area. The third one will be the suggestion of the plausibility of an evolutionary scenario for the origins of language close to the scenario proposed by Darwin and Wallace to take into account the so-called "sexual selection". The fourth one refers to the hypothesis by ethologists that close links exist between play behaviours and evolution of language. 


\section{Conclusion}

If biosemiotics is seen as the field of the emergence of meaning in natural world, we have to re-evaluate two major phenomena: interspecies communications, and in particular the break that occurred with the human being as a creature capable of being a "universal interlocutor" for the first time, and the role of pleasure in the emergence of a complex semiotic natural system as language. ${ }^{11}$

\section{References}

Bates, Elizabeth 1979. Language and Context: The Acquisition of Pragmatics. New York: Academic Press.

Byrne, Richard; Whiten, Andrew (eds.) 1988. Machiavellian Intelligence: Social Expertise and the Evolution of Intellect in Monkeys, Apes, and Humans. Oxford: Oxford University Press.

Fouts, Roger Sheridan; Fouts, Deborah H. 1989. Loulis in conversation with the cross-fostered chimpanzees. In: Gardner et al. 1989: 293-307.

Gardner, R. Allen; Gardner, Beatrix T.; Cantfort, Thomas E. Van (eds.) 1989. Teaching Sign Language to Chimpanzees. Albany: State University of New York Press.

Hauser, Marc 1996. Evolution of Communication. Cambridge: Harvard University Press.

Kellogg, W. N., 1968. Communication and language in the home-raised chimpanzee. Science 162: 423-427.

Lestel, Dominique 2001. Les Origines Animales de la Culture. Paris: Flammarion.

- 2002. The biosemiotics and phylogenesis of culture. Social Science Information (in press).

Milevska, Suzana 2000. From a bat's point of view. In: Kostic, Aleksandra; Dobrila, Peter Tomaz (eds.), Eduardo Kac: Telepresence, Biotelematics, Transgenic Art. Maribor: KIBLA, 47-58.

Rumbaugh, D.; Pate, J. 1984. The evolution of cognition in primates: A comparative perspective. In: Roitblat, H. L.; Bever, T. G.; Terrace, H. (eds.), Animal Cognition. Hillsdale: Lawrence Erlbaum Associates, 569-587.

Savage-Rumbaugh, E. Sue 1986 Ape Language: From Conditioned Responses to Symbols. New York: Columbia University Press.

- 1990. Language as a cause-effect communication system. Philosophical Psychology 3: 55-76.

Turing, Alan 1959. Computing machinery and intelligence. Mind 59: 434-469.

\footnotetext{
${ }^{11}$ I wish to thank Jesper Hoffmeyer for fruitful comments on my paper
} 


\section{Общение между человеком и животным, язык и эволюция}

В статье сравниваются разные исследовательские программы, занимающиеся обучением шимпанзе символическому языку. Рассматриваются две дихотомии: искусственный язык - язык жестов; исследователи, решившие установить эмоциональную связь между собой и обезьянами, - исследователи, видевшие в обезьянах лишь инструментальные средства. Делается вывод, что весьма интересные результаты были получены при использовании как искусственного языка, так и языка жестов, и особенно в условиях, когда между экспериментаторами и обезьянами существовала тесная связь. Эксперименты с говорящими обезьянами являются не столько психолингвистическими опытами (в какой мере животные могут научиться человеческому языку), сколько великолепными примерами коммуникачионного сообщества между людьми и большими обезьянами.

\section{Inimese ja looma vaheline suhtlemine, keel, evolutsioon}

Artiklis võrreldakse erinevaid uurimisprogramme, mis tegelevad sümbolilise keele õpetamisega šimpansitele. Vaadeldakse erinevusi kahe dihhotoomia kunstlike keelte ja viipekeelte, ning nende uurijate, kes otsustasid kujundada emotsionaalse suhte enda ja ahvide vahel, ja teiste, kes nägid ahvides instrumentaalseid vahendeid - osas. Järeldatakse, et väga huvitavaid tulemusi saadi nii kunstlike keelte kui viipekeele korral, kuid eelkõige juhul, kui uurijate ja loomade vahel oli eksperimendis tihe side. Eksperimendid kõnelevate ahvidega pole niivõrd eksperimendid psühholingvistikast (s.o. millises ulatuses suudavad loomad õppida inimkeelt), kuivõrd suurepärased eksperimendid suhtlemiskooslusest inimeste ja suurte ahvide vahel. 